\title{
Editorial
}

\section{Ants and Their Parasites}

\author{
Jean-Paul Lachaud, ${ }^{1,2}$ Alain Lenoir, ${ }^{3}$ and Volker Witte ${ }^{4}$ \\ ${ }^{1}$ Centre de Recherches sur la Cognition Animale, CNRS-UMR 5169, Université de Toulouse, UPS, 118 route de Narbonne, \\ 31062 Toulouse Cedex 09, France \\ ${ }^{2}$ Departamento de Entomología Tropical, El Colegio de la Frontera Sur, Avenida Centenario Km. 5.5, AP 424, \\ 77014 Chetumal, QRoo, Mexico \\ ${ }^{3}$ IRBI, UMR CNRS 7261, Faculté des Sciences, Université François Rabelais, Parc de Grandmont, 37200 Tours, France \\ ${ }^{4}$ Department Biologie II, Ludwig-Maximilians Universität München, Großhaderner Straße 2, 82152 Planegg-Martinsried, Germany \\ Correspondence should be addressed to Jean-Paul Lachaud, jlachaud@ecosur.mx
}

Received 23 February 2012; Accepted 23 February 2012

Copyright ( $\odot 2012$ Jean-Paul Lachaud et al. This is an open access article distributed under the Creative Commons Attribution License, which permits unrestricted use, distribution, and reproduction in any medium, provided the original work is properly cited.

Ants accumulate and protect collective resources and, with the exception of nomadic species, live in a nest which is considered to be one of the bases of the evolution of eusociality. Resources and/or protective services provided by ant colonies are exploited in manifold ways by an amazing diversity of other organisms acting as guests and/or parasites: viruses, bacteria, fungi, sporozoa, amoeba, ciliates, nematodes, trematodes, cestodes, mollusks, diplopods, crustaceans, mites, spiders, and a large variety of parasitic or parasitoid insects. Such associations can be obligatory or facultative, permanent or temporary, harmful or beneficial for the host. Due to the diversity of interactions, an understanding of the nature of these relationships and the mechanisms of integration used by parasites as well as the defense strategies developed by their potential host remains a challenge. Parasites certainly increase specific selection pressures on colony phenotype, and they may also shape the composition and dynamics of ant communities. Over the past two decades there has been a growing interest in the impact of parasites on colony phenotype, and their role in the ecology and evolution of their hosts. Despite the apparent importance of ant parasites, detailed knowledge is lacking, for example, about their diversity and abundance or selection pressures imposed through parasitism on host reproductive strategies.

Parasitism in ants has attracted the attention of numerous scientists in the last two centuries (see the numerous publications on this topic by authors like E. W. Janson, A. Forel, C. Janet, E. Wasmann, H. Viehmeyer, J.-J. Kieffer, K. Escherich, W. M. Wheeler, H. St. J. K. Donisthorpe, W. M. Mann, C. Rettenmeyer, E. O. Wilson, B. Hölldobler,
D. Kistner, U. Maschwitz, and P. Schmid-Hempel among others). Since the synthesis of Kistner in 1982 [1] and of Schmid-Hempel in 1998 [2], only one complete review has been published [3] (but see also [4] for social parasites) and, in spite of the accumulation of much information in the last decades, this meaningful topic has not been brought together in a specific issue for a long time. This special issue, of course, cannot cover all possible ant parasites, but it examines a wide range of species: viruses, bacteria, fungi, nematodes, silverfishes, flies, butterflies, beetles, spiders, wasps, and ants themselves. It is divided into two main sections: (1) behavioral and ecological aspects of parasitism, in which existing associations are reviewed and discussed, some new associations are described, and some concepts are reanalyzed in a more up-to-date integrative vision; (2) infection, impact on ants and biological control, in which particular effort has been made to provide both an analytical review of the experimental material actually available and a proposal of guidelines for future research on the topic.

Behavioral and Ecological Aspects of Parasitism. Numerous species take advantage of the supplies of other organisms and cleptobiosis, a quite common phenomenon among animals, also occurs at ants' expenses. M. D. Breed et al. review concepts linked to food stealing in social insects, distinguishing cleptobiosis from some related phenomena, and place this knowledge in ecological and evolutionary contexts. In most cases, success in parasitizing ants depends largely on the degree of resemblance to the host, which varies considerably among the diverse mimetic parasites found in 
ant societies. Different morphological, behavioral, and/or chemical adaptations allow cleptoparasites to deceive ant defense mechanisms. Reviewing more especially the use of the terms that describe the chemical resemblance between the cuticular chemical profiles of parasites and that of their hosts, C. von Beeren et al. give an overview of cases concerning adaptive chemical resemblance and propose a terminology more consistent with that generally used in biology: "chemical crypsis" when the operator (the host) does not detect the mimic as a discrete entity and "chemical masquerade" when the operator detects the mimic but misidentifies it as an uninteresting entity.

The reports of adaptive resemblance (visual, morphological, and/or chemical) are amazingly numerous. Spider-ant associations, for example, involving either myrmecomorphy, myrmecophily or myrmecophagy, or a combination of the three, are very common, and P. E. Cushing provides an excellent update of her important 1997 review [5] with a welcome summary of recent work testing the adaptational significance of these associations. Among spiders, myrmecomorphy is supposed to usually involve Batesian mimicry but such an assumption has not been demonstrated experimentally. X. J. Nelson provides the first evidence that salticid ant mimicry is truly Batesian mimicry. She shows experimentally both that ant mimicry is perceived by the predator and has a protective effect for the mimic, and how a predatory spider is affected by the degree of visual resemblance of ant mimics to ants.

Among the myrmecophiles, the Coleoptera are probably the most diverse group. In some cases, associations have been known for a long time but the behavioral adaptations allowing the integration of the parasite remain poorly studied. Through a quantitative analysis, E. Maurizi et al. show that the rewarding behavior, during which the ground beetle Paussus favieri provides attractive chemical substances to its host Pheidole pallidula, is one of the key factors for acceptance and full integration in the ant society. Another way of deceiving a host is through innate chemical mimicry (sensu C. von Beeren et al.), involving a change in the parasite's chemical profile in accordance with the host nest odor. This is what A. Lenoir et al. report for a histerid and a staphylinid beetle, both of which parasitize Aphaenogaster senilis, whereas a silverfish that shares the same host shows only low quantities of host hydrocarbons, which are probably acquired passively. After isolation, the histerid beetles Sternocoelis hispanus keep their hydrocarbon quantity, showing that they are able to synthesize them and adjust their profile to the host colony via direct contacts. This is the first such demonstration in a myrmecophile beetle. In all the other cases studied, the hydrocarbons are provided by the host as occurs, for example, in Malayatelura ponerophila, a kleptoparasitic silverfish of Leptogenys distinguenda [6]. Various species, like many coccinellids, indirectly affect ants through their predation on trophobiotic Hemiptera. Possibly, frequent interactions with ants led some species to become myrmecophilous and to use chemical mimicry to get close to their prey. A. Vantaux et al. provide an overview of the evolution of myrmecophilous traits in ladybirds and discuss from an evolutionary perspective both costs and benefits of myrmecophily and even dietary shifts to myrmecophagy, which occurred in a few species. By comparison, the myrmecophagy on leaf-cutter ant queens by dung beetles of the genus Canthon is a much better known phenomenon, even if behavioral studies are scarce. L. C. Forti et al. present in their thorough behavioral study many details on how Canthon virens attacks Atta queens.

Besides hemipterans, numerous butterflies species are associated mutualistically with ants, and species from the family Lycaenidae are among the best studied. Interestingly, associations also changed towards parasitic interactions several times. K. Fiedler presents a comprehensive review of the host ants of parasitic lycaenids and analyzes the macroecological patterns that could be related with the use of particular ant genera as hosts. His large-scale survey reveals that those ant genera in which associations with lycaenids are particularly numerous are also more likely to serve as hosts for parasitic species. Among lycaenids, associations between the genus Maculinea and the ant genus Myrmica are certainly the most investigated. F. Barbero et al. present an overview of the adaptations used by Maculinea butterflies to infiltrate and live as parasites in Myrmica ant colonies, and more particularly, based on a synthesis of recent research, how they mimic the acoustic communication of their hosts. Some other parasitic butterflies are less well known, and L. A. Kaminski and F. S. Carvalho-Filho describe and illustrate for the first time the immature stages of Aricoris propitia and uncover the diversity of life cycles in the still enigmatic butterfly family Riodinidae.

A large number of parasitoid species have been reported in association with ants but, most often, the true nature of their relationships is poorly known and few species are really highly specialized on ants in general. High specialization on ants is however the case in various genera of phorid flies and in numerous species of wasps from three superfamilies: Chalcidoidea, Ichneumonoidea, and Diaprioidea. B. V. Brown and S. M. Philpott describe three new species of Pseudacteon flies with some details on the natural history of the ant-fly interaction and provide a useful taxonomic key to the species. Successful parasitism by phorids involves utilization of multimodal cues to locate and recognize the host. K. A. Mathis and S. M. Philpott review some important components of phorid biology, and the variety of strategies and cues used by the three most common phorid genera attacking ants (Apocephalus, Pseudacteon, and Neodohrniphora). Apart from their direct parasitic effects on ants, phorid flies also affect their behavior, and H.Y. Hsieh and I. Perfecto review the impact of parasitoid phorids on ants and other organisms that interact with ants. They focus both on the variety of mechanisms used by ants to cope with phorid parasitism and on the complexity of these interactions through trait-mediated indirect effects on other trophic levels. Finally, in an attempt to understand how parasitoids affect their host ants' foraging success in a community framework involving species of different body size and behavioral dominance, E. B. Wilkinson and D. H. Feener Jr. examine how habitat structural complexity affects the foraging behavior of two species of the genus Pheidole by interacting with parasitoids of the genus Apocephalus. Hymenopterous parasitoids of ants also exhibit a wide 
array of adaptations to attack such potentially dangerous hosts. Reports of parasitoid wasps associated with ants are numerous but real primary parasitoidism has rarely been proven. J.-P. Lachaud and G. Pérez-Lachaud review all of the cases for which such primary parasitoidism has reliably been established, providing an updated list of at least 138 species from 9 families. They report some new associations and focus both on the diversity of these parasitoid wasps and the diversity of the types of interactions they have formed with their ant hosts. Among these hymenopteran parasitoids of ants, the eucharitid family has been particularly under scrutiny for the last three decades, especially the genus Kapala, the most common in the Neotropics [7]. A. A. Vásquez-Ordóñez et al. present useful natural history information on the interactions between a Kapala species and the host ant Ectatomma ruidum in Colombia. Evaluating the effect of habitat type on eucharitid parasitism, they report a significantly higher prevalence of parasitism in host ant colonies in woodland compared to grassland habitat.

Infection, Impact on Ants and Biological Control. In numerous applied studies on ant parasitism, specific attention has been given to the ways in which parasite pressure may affect patterns of life history in ant hosts. For example, generalist entomopathogenic fungi could be used in biological control of pest ants as discussed by M. M. R. Ribeiro et al. in the case of Beauveria bassiana and Aspergillus ochraceus against the grass-cutting ant Atta bisphaerica, one of the most important pests of pastures and crops in Brazil. It is the first time that A. ochraceus is reported to infect Atta with a high prevalence. However, field experiments are necessary to test for their effect as biological control. Pathogens are difficult to identify because sick or dying ants are promptly removed from the nest or leave the nest themselves (see the recent review by Shorter and Rueppell [8]). Some entomopathogenic fungi are ant specific and X. Espadaler and S. Santamaria review what is known concerning the taxonomy, natural history, and/or ecology of ecto- and endoparasitic fungi specialized on ants throughout the Holarctic region. The fungi considered in this paper show a gradient of negative effects on the host, and their specificity does not seem to be always very strict since various fungi are known from a range of hosts (e.g., Laboulbienna; formicarum is hosted by 24 ant species belonging to 3 formicine tribes). Specificity is apparently higher both in the mutualistic basidiomycetous fungi cultivated for food by neotropical fungus-growing ants of the tribe Attini, and the specialized microfungal parasites which coevolved with these associations and have a negative impact on the fungus gardens. Recent research on this issue has provided novel insights into coevolution, antibiotic defense mechanisms, and behavioral interactions within symbiotic systems. F. C. Pagnocca et al. pulled together diverse literature and present a review of the microfungi associated with leaf-cutting ant gardens, while S. H. Yek et al. synthesize our current understanding on the evolution of specialized parasites of the attine fungus gardening system. Using a modified version of Tinbergen's four categories of evolutionary questions to structure their review, they focus on development, mechanism, adaptation, and evolutionary history and suggest further directions for investigations of this symbiosis.

Various other organisms, in addition to entomopathogenic fungi, can affect the biology of their hosts. Bacteria of the genus Wolbachia, for example, are known to alter the reproductive capabilities of their hosts significantly, showing complex interactions with them, which, in some cases, have evolved to symbiotic associations. K. K. Ingram et al. examine possible parameters affecting the spread of Wolbachia infections in a newly established population of Formica fusca. Their results show that horizontal transmission of Wolbachia is apparently uncommon and that there are no marked fitness differences between infected and noninfected colonies. This is an additional illustration of the complex role of Wolbachia in ants which is not yet explained $($ see $[9,10])$. Ants can also serve as hosts of a variety of internal or external parasitic nematodes from several families with more or less complex life cycles. Different entomopathogenic nematodes like Steinernema and Heterorhabditis have been suggested to control ants through inundative applications. The current state of knowledge regarding the occurrence, systematics, life history, and pathology of all described nematodes associated with formicids is summarized by G. Poinar Jr. through a richly illustrated review. Apart from including a simple key to the higher taxa of ant-infecting nematodes, he identifies the large gaps that exist in our understanding of this very interesting system.

The use of ant parasites as a means of biological control has been most heavily investigated in relation to one of the most important pests in the New World, the imported fire ants (Solenopsis). Focusing their review on research programs that have been carried out over 25 years in their laboratory, J. Briano et al. give a wide panorama of the natural enemies of fire ants (microsporidia, nematodes, viruses, phorid flies, eucharitid wasps, myrmecolacid strepsipteran, and social parasitic ants). They summarize published information and include many complementary unpublished observations. Among these natural parasites, a more special focus is given by S. M. Valles about the research on viruses through a compilation of the literature on fire ant viruses, and a review on the properties of three particular viruses infecting $S$. invicta. It is worth noting that viruses were unknown in any ant species before the first discover by Valles and colleagues in 2004 [11], and this topic will certainly be a central issue in fire ants control programs in the future. Finally, the evaluation of the use of Pseudacteon parasitoid flies as potential biological control agents of invasive Solenopsis fire ants is critically and exhaustively reviewed by L. W. Morrison. The sound conclusions of this review about the realities of biological control of fire ants by phorid flies contrast with most of the literature on that topic and emphasize the necessity of a battery of complementary natural enemies, in addition to the release of phorid flies, for potentially successful regulatory effects on fire ant populations. This points to a need for investing more effort into studies on other potential control agents.

More and more studies show a fascinating coevolution between parasites and their hosts. An accurate survey of this topic will provide useful information to refine our understanding of both the mechanisms involved and their 
phylogenitical and evolutionary components. With the growing interest in biodiversity, we realize that we are far from concluding our assessment of existing forms of parasitism. Considering the increasing losses in biodiversity due to habitats restructuration and climatological changes, the urgent need for making such inventories is obvious. The world of the microorganisms is one of the most promising. For example, G. Poinar Jr. indicates that some 20,000 nematodes have been described, while their species diversity has been estimated to be as high as 10 million, and even if the proportion of known species associated with ants is low, their real number is surely much more impressive than actually suggested. A metagenomics approach will be useful in the future; it has already begun in honeybees [12] and in termites [13] and is just starting up in ants [14]. Parasites contribute to maintaining complex ecosystems and have a role in stabilizing mutualisms as observed in fungus-growing ants [15]. Their role as a "top-down" process, structuring ant communities and populations, is also considered to be important. Some authors, like Feener [16], suggest that the assembly of ant communities is mediated by parasitoids. Others $[2,17,18]$ suspect that parasites and parasitoids may be involved in the emergence of alternative reproductive strategies such as polygyny and/or multiple mating (polyandry), by inducing an enhancement in the genetic diversity of the workers that would increase resistance to parasites and pathogens (but see [19]). Recent data on the evolution of elaborate mushroom bodies in the brains of hymenopteran insects even suggest that the neurobehavioral modifications linked to the capacity for associative and spatial learning during host-finding behavior in parasitoids may have served as preadaptations for central place foraging in social hymenopterans [20]. Ants (and, more generally, social insects) and their parasites are an exceptional model. In the next years, more studies examining their complex interactions from every possible angle, attempting to bring a more global vision of the functioning of such an evolutionary important relationship, will surely constitute a challenging and fascinating goal for us and many colleagues.

\section{Acknowledgments}

The guest editors would like to thank all of the authors who accepted to participate in the challenge of giving rise to this special issue. Particular thanks are due to the numerous referees who generously helped us to make this special issue possible. We are also grateful to Tomer Czaczkes both for his helpful advices and useful suggestions on an earlier draft of this paper and for English improvement.

Jean-Paul Lachaud

Alain Lenoir

Volker Witte

\section{References}

[1] D. H. Kistner, "The social insects' bestiary," in Social Insects, H. R. Hermann, Ed., vol. 3, pp. 1-244, Academic Press, New York, NY, USA, 1982.
[2] P. Schmid-Hempel, Parasites in Social Insects, Princeton University Press, Princeton, NJ, USA, 1998.

[3] J. J. Boomsma, P. Schmid-Hempel, and W. O. H. Hugues, "Life histories and parasite pressure across the major groups of social insects," in Insect Evolutionary Ecology, M. D. E. Fellowes, G. J. Holloway, and J. Rolff, Eds., pp. 139-175, CAB International, Wallingford, UK, 2005.

[4] D. R. Nash and J. J. Boomsma, "Communication between hosts and social parasites," in Sociobiology of Communication: an Interdisciplinary Perspective, P. D'Ettorre and D. P. Hugues, Eds., pp. 55-79, Oxford University Press, Oxford, UK, 2008.

[5] P. E. Cushing, "Myrmecomorphy and myrmecophily in spiders: a review," Florida Entomologist, vol. 80, no. 2, pp. 165193, 1997.

[6] C. von Beeren, S. Schulz, R. Hashim, and V. Witte, "Acquisition of chemical recognition cues facilitates integration into ant societies," BMC Ecology, vol. 11, article 30, 2011.

[7] J.-P. Lachaud, P. Cerdan, and G. Pérez-Lachaud, "Poneromorph ants associated with parasitoid wasps of the genus Kapala Cameron (Hymenoptera: Eucharitidae) in French Guiana," Psyche, vol. 2012, Article ID 393486, 6 pages, 2012.

[8] J. R. Shorter and O. Rueppell, "A review on self-destructive defense behaviors in social insects," Insectes Sociaux, vol. 59, no. 1, pp. 1-10, 2012.

[9] J. A. Russell, “The ants (Hymenoptera: Formicidae) are unique and enigmatic hosts of prevalent Wolbachia (Alphaproteobacteria) symbionts," Myrmecological News, vol. 16, pp. 7-23, 2012.

[10] C. Martins, R. F. Souza, and O. C. Bueno, "Presence and distribution of the endosymbiont Wolbachia among Solenopsis spp. (Hymenoptera: Formicidae) from Brazil and its evolutionary history," Journal of Invertebrate Pathology, vol. 109, no. 3, pp. 287-296, 2012.

[11] S. M. Valles, C. A. Strong, P. M. Dang et al., "A picorna-like virus from the red imported fire ant, Solenopsis invicta: initial discovery, genome sequence, and characterization," Virology, vol. 328, no. 1, pp. 151-157, 2004.

[12] D. L. Cox-Foster, S. Conlan, E. C. Holmes et al., "A metagenomic survey of microbes in honey bee colony collapse disorder," Science, vol. 318, no. 5848, pp. 283-287, 2007.

[13] F. Warnecke, P. Luginbühl, N. Ivanova et al., "Metagenomic and functional analysis of hindgut microbiota of a woodfeeding higher termite," Nature, vol. 450, no. 7169, pp. 560$565,2007$.

[14] H. D. Ishak, R. Plowes, R. Sen et al., "Bacterial diversity in Solenopsis invicta and Solenopsis geminata ant colonies characterized by $16 \mathrm{~S}$ amplicon 454 pyrosequencing," Microbial Ecology, vol. 61, no. 4, pp. 821-831, 2011.

[15] A. E. F. Little and C. R. Currie, "Parasites may help stabilize cooperative relationships," BMC Evolutionary Biology, vol. 9, article 124, 2009.

[16] D. H. Feener Jr., "Is the assembly of ant communities mediated by parasitoids?" Oikos, vol. 90, no. 1, pp. 79-88, 2000.

[17] M. G. Gardner, K. Schönrogge, G. W. Elmes, and J. A. Thomas, "Increased genetic diversity as a defence against parasites is undermined by social parasites: Microdon mutabilis hoverflies infesting Formica lemani ant colonies," Proceedings of the Royal Society B, vol. 274, no. 1606, pp. 103-110, 2007.

[18] W. O. H. Hughes, F. L. W. Ratnieks, and B. P. Oldroyd, "Multiple paternity or multiple queens: two routes to greater intracolonial genetic diversity in the eusocial hymenoptera," Journal of Evolutionary Biology, vol. 21, no. 4, pp. 1090-1095, 2008. 
[19] G. Pérez-Lachaud, J. E. Valenzuela, and J.-P. Lachaud, "Is increased resistance to parasitism at the origin of polygyny in a Mexican population of the ant Ectatomma tuberculatum (Hymenoptera: Formicidae)?" The Florida Entomologist, vol. 94, no. 3, pp. 677-684, 2011.

[20] S. M. Farris and S. Schulmeister, "Parasitoidism, not sociality, is associated with the evolution of elaborate mushroom bodies in the brains of hymenopteran insects," Proceedings of the Royal Society B, vol. 278, no. 1707, pp. 940-951, 2011. 

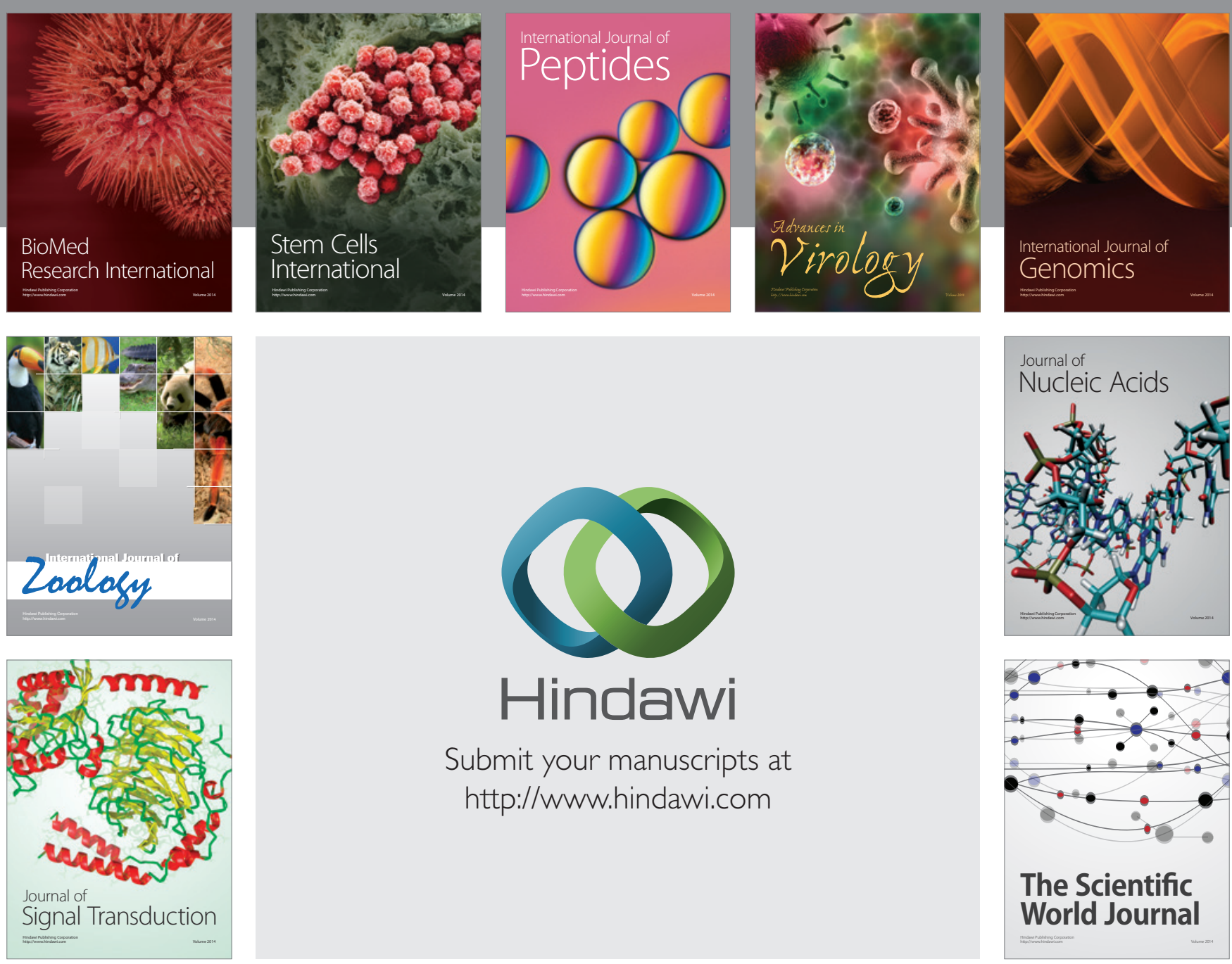

Submit your manuscripts at

http://www.hindawi.com
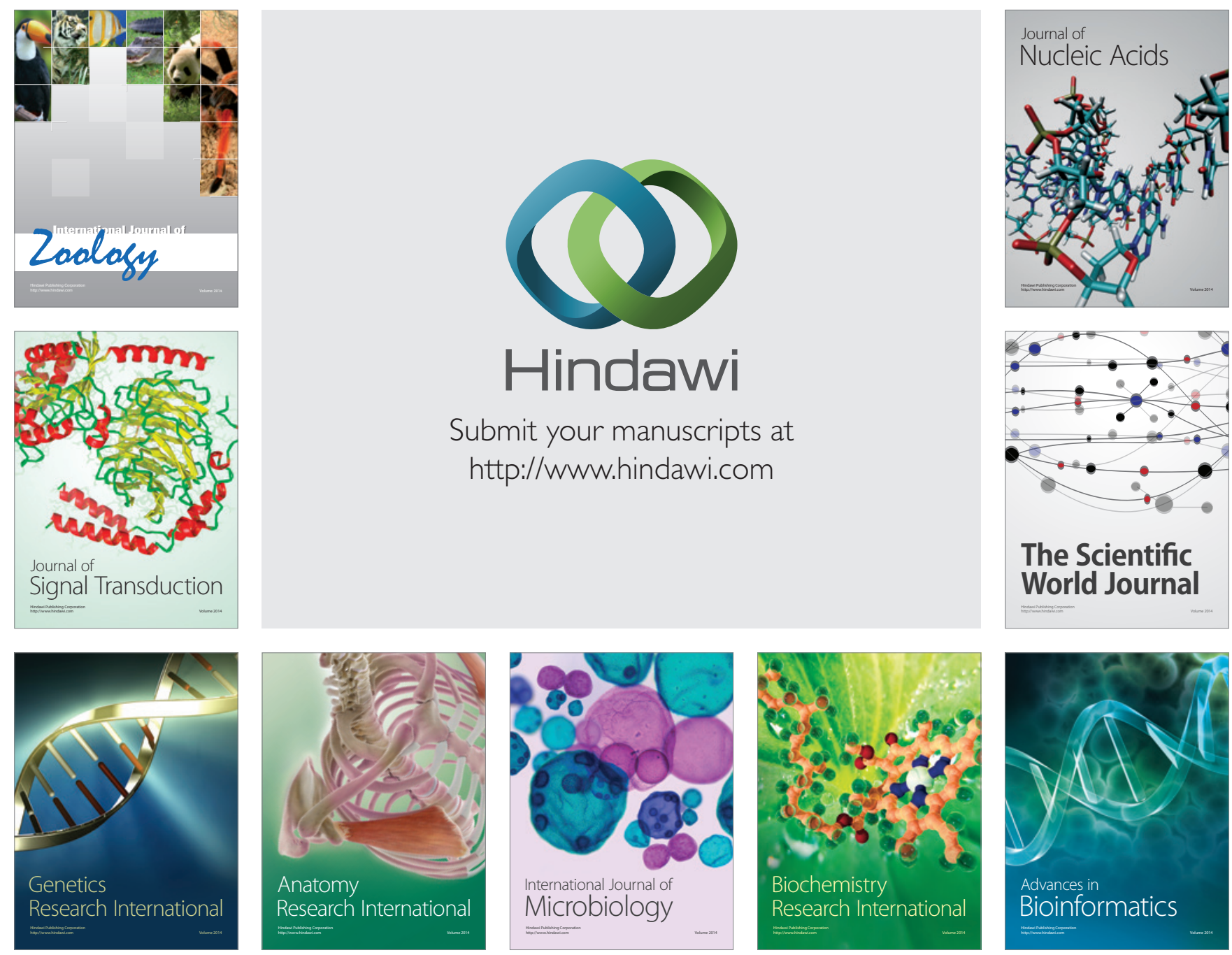

The Scientific World Journal
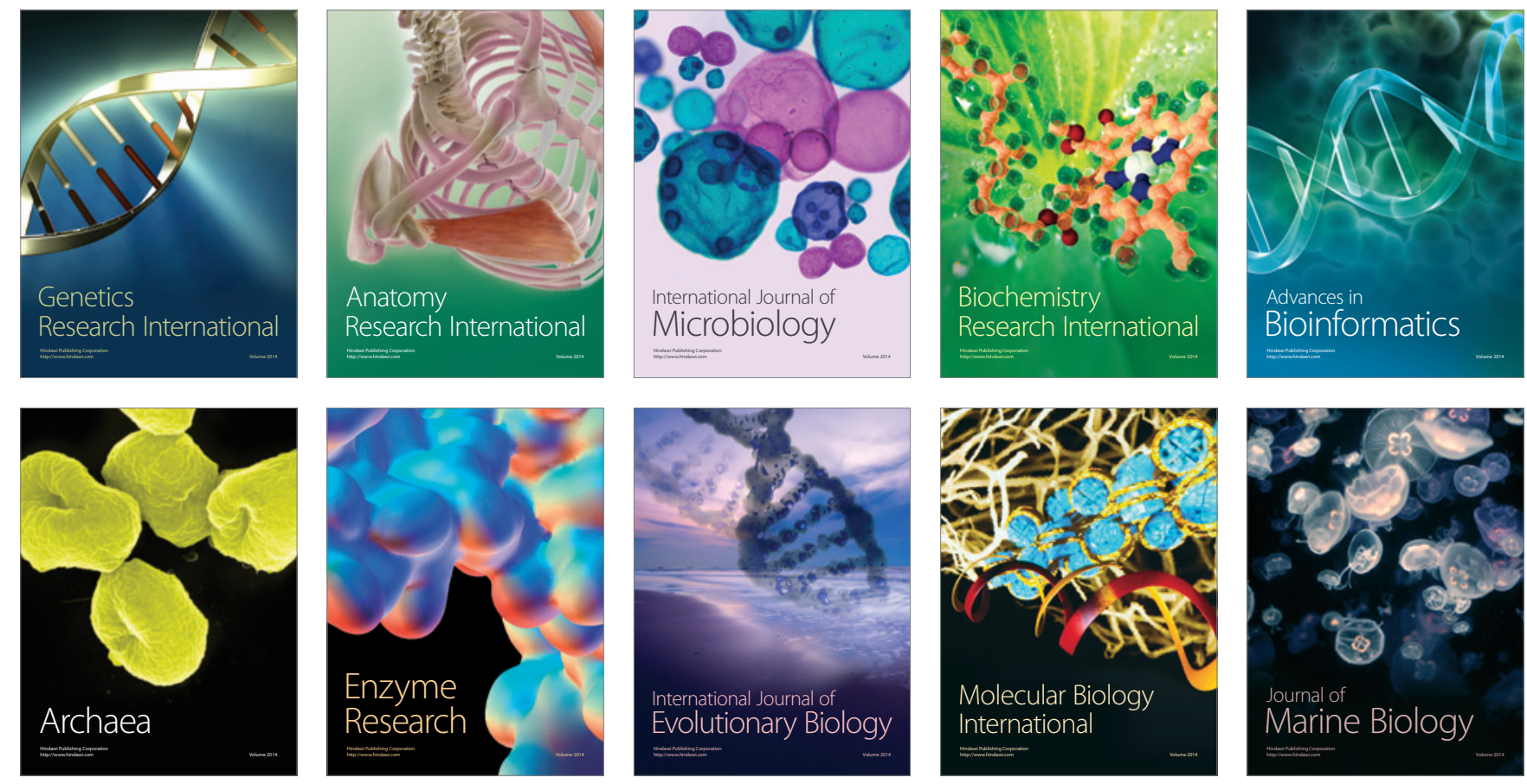